\title{
Teaching for transfer between first and foreign language classroom contexts: Developing a framework for a strategy-based, cross-curricular approach to writing pedagogy
}

\author{
Karen Forbes \\ University of Cambridge, Cambridge, UK
}

\begin{abstract}
Writing is a skill which is actively taught in both first (L1) and foreign language (FL) classrooms, yet surprisingly few cross-curricular links are made. This paper, aimed at both practitioners and researchers, presents a framework for designing and implementing a strategy-based, cross-curricular approach to writing pedagogy in schools. It first considers the factors which should be taken into account when designing such an intervention in both L1 and FL classrooms. It then outlines the key steps in the implementation of such a programme of strategy-based instruction. To exemplify this, the paper reports on data throughout from an empirical study involving a classroom intervention of explicit strategy-based instruction which was delivered first in the German FL classroom, and later also in the English classroom of a Year 9 (age 13-14) class in a secondary school in England. The aim was to help students to develop their writing strategies and to encourage transfer between languages. Findings suggest that while a programme of strategy-based instruction can improve strategy use and attainment in writing within a particular language context, effects are most powerful when there is collaboration between L1 and FL teachers. Evidence therefore calls for a multilingual approach to writing pedagogy.

KEYWORDS: WRITING; LANGUAGE LEARNING STRATEGIES; CROSS-CURRICULAR; TRANSFER; FOREIGN LANGUAGE; FIRST LANGUAGE
\end{abstract}

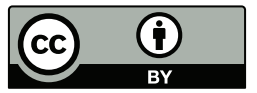

This work is licensed under a Creative Commons Attribution 4.0 International License.

\section{Affiliation}

Faculty of Education, University of Cambridge, Cambridge, UK Email: kf289@cam.ac.uk 


\section{Introduction}

Developing the ability to communicate effectively in writing is a skill which permeates the entire school curriculum and one which is vitally important for future success in the workplace. However, within the context of secondary school language classrooms, developing competence in writing represents a particular challenge for many learners, particularly in a foreign language, but often also in their native language. Unlike speaking, which can be acquired naturally provided there is a sufficient level of input and exposure, writing is a skill which has to be learned and consciously developed. Yet, while first language (L1) and foreign language (FL) teachers in secondary schools in England both assume some responsibility for teaching writing, they often have very different approaches and priorities. As a result, few cross-curricular links are made (Pomphrey and Burley, 2009) and opportunities have been lost to acknowledge the contribution of foreign language teachers to the understanding and use of language in general. The aim of this paper is therefore to present a framework for designing and implementing a strategy-based, cross-curricular approach to writing pedagogy, where secondary school English and FL teachers work together to encourage connection-making and improve writing skills across language contexts.

\section{English and FL teaching in secondary schools in England}

In secondary schools in England there is increasing concern about the declining number of students who choose to study a language beyond the compulsory phase (Tinsley and Board, 2017). Even where the study of languages is a curricular entitlement (between the ages of 7 and 14), there is a growing trend in schools which exclude or excuse students from FL lessons in favour of receiving extra literacy support in English or because they are not considered to be 'successful' language learners. There is therefore a need to promote the FL classroom as a key context for developing not only valuable communicative skills in the foreign language itself, but also important transferable skills related to language more generally.

English, conversely, has consistently enjoyed a higher status in schools as a 'core' or 'foundation' subject. A report by the schools' inspectorate in England (OFSTED, 2012: 4) begins with the statement that: 'there can be no more important subject than English in the school curriculum. English is a pre-eminent world language, it is at the heart of our culture and it is the language medium in which most of our students think and communicate'. However, as suggested by Burley and Pomphrey (2003), the high status of the English language in the school as a whole may paradoxically interfere 
with the way in which it is presented as a subject. This can make it difficult to study English as a language in a sufficiently objective way.

As a result, English and FL departments in schools in England often have very different approaches and priorities when it comes to the teaching of writing. First language teachers, who can often assume a certain level of proficiency among learners, are more likely to take a subconscious, synthetic, top-down approach, while foreign language teachers tend to take a more conscious, analytical, bottom-up approach (Kecskes and Papp, 2000). As such, it seems fair to say that 'students' perceptions about language are unlikely to be very coherent if the underlying attitudes and perceptions of their teachers of English and foreign languages differ so widely and the teachers are not engaged in dialogue about the differences' (Pomphrey and Moger, 1999: 224).

The potential for developing cross-curricular links was highlighted by the schools' inspectorate (OFSTED, 2013: 4) in their report on improving standards in literacy. The report recommends that the curriculum should offer the opportunity for students to 'develop writing skills through work that makes cross-curricular links with other subjects' and calls for longterm planning and more collaboration between teachers in different subject areas. FL teachers, therefore, who are able to focus more explicitly on the development of language learning strategies, are in a unique position to contribute to the overall improvement in writing standards (Forbes, 2018a).

\section{Literature review}

It was in light of this consideration of the potential contribution of FL teachers to writing development more generally that the current study, which focuses on language learning strategies, was conceived. Language learning strategies are generally considered as a means of ensuring that language is stored, retained and able to be produced when necessary; that is, they affect learning directly. They are 'optional' (Bialystok, 1978: 69), 'consciously selected by the learners' (Cohen, 1998: 4) and the aim of learning strategies according to O'Malley and Chamot (1990: 1) is to 'enhance comprehension, learning or retention of new information'. The current study focuses particularly on developing strategies with a metacognitive function, which involve thinking about the learning process, planning for learning, monitoring of comprehension or production while it is taking place, and self-evaluation after the learning activity has been completed' (O'Malley and Chamot, 1990: 8). This focus is due to evidence of a correlation between learners' success and the use of metacognitive strategies (Cohen, 2011; Griffiths, 2013; Oxford, 2017), and also the importance of 
metacognition in maintaining strategy use over time and transferring strategies to new tasks.

The decision to focus on the skill area of writing as the context for the current study was similarly influenced by several factors. Writing, particularly in a foreign language, is arguably the most difficult of the modalities in which to achieve communicative competence' (Chamot, 2005: 121), and therefore students will likely benefit from developing strategies to aid them with such a cognitively demanding task. Vygotsky (1962) similarly argued that writing requires a high level of abstraction and demands both conscious work and deliberate action. As such, the associated strategies lend themselves more easily to classroom-based instruction in both first and foreign language contexts.

It is important to acknowledge that the study of writing strategies in particular is also situated within a wider research movement known as 'process writing' which emerged in the field of native language composition research 'with the aim of gaining insights into the mental actions writers engage in while composing' (Manchón, Roca de Larios, and Murphy, 2007: 229). Within the field of L1 writing, it was Hayes and Flower (1980) who pioneered this more strategic approach to writing instruction with the development of their Cognitive Process Model, which initially viewed writing as a writer-centric, goal-oriented, problem-solving task. Within the field of second language acquisition, research into writing strategies has similarly been on-going since the 1980 s, yet during this time was primarily concerned with the identification, description and comparison of strategies of 'good' and 'poor' learners (e.g. Cumming, 1989; Jones and Tetroe, 1987; Raimes, 1987; Zamel, 1983).

However, from the mid-1990s, such cognitively-oriented research attracted criticism for neglecting the sociocultural context and more emic perspectives of writing. It was then suggested that writing should be considered as 'a sociocognitive activity which involves skills in planning and drafting as well as knowledge of language, contexts, and audiences' (Hyland, 2002: 23). This sociocognitive perspective on writing in turn influenced pedagogy and research in both first and foreign language contexts. It resulted in increasing attention being paid to the role of learners' individual differences with regard to strategy use and to the role of teachers as 'co-constructors' of learning strategies (Collins, 1998). A methodological shift also occurred, moving from a focus on a writer's individual cognitive processes by means of verbal protocols in artificial conditions, to a consideration of writing in an authentic social environment such as a classroom.

More recently, however, focus has shifted to the active development of strategies through programmes of strategy-based instruction (SBI). Some studies have been conducted into the influence of an intervention of 
strategy-based instruction in either an L1 context (e.g. Bouwer, Koster, and van den Bergh, 2018; De La Paz and Graham, 2002; Graham and Harris, 2003; MacArthur, Philippakos, and Ianetta, 2015), or a foreign/second context (e.g. Bai, 2015; Dan, 2017; De Silva and Graham, 2015; Macaro, 2001; Sasaki, 2000; Sengupta, 2000), and on the whole have shown positive effects on the performance of those who received writing strategy instruction. The positive effects of SBI on language learning have similarly been highlighted in a recent meta-analysis by Ardasheva et al. (2017). Based on these studies, a series of pedagogical models of strategy-based instruction have been developed and implemented with secondary and tertiary level learners in a range of contexts (e.g. Graham, Harris, and Mason, 2005; Macaro, 2001; Oxford, 2011). The key characteristics of such models will be discussed further below.

However, it is important to note that the vast majority of this research has taken place within a single context of either L1 or FL education and has had a tendency to neglect the potential interactions between the two. In addition, it is almost taken for granted within the literature that any reference to transfer between these two contexts implies the one-way transfer of pre-existing skills and strategies from the L1 to the FL. Studies which explore phenomena such as language transfer (Odlin, 1989) or crosslinguistic influence (Sharwood Smith, and Kellerman, 1986), for example, tend to focus on the L1 to FL transfer of linguistic systems, such as lexical items, syntax, phonology or morphology rather than strategies. It is also important to acknowledge that L1 strategies may not necessarily be effective; as explored by Flower and Hayes (1981) and Bereiter and Scardamalia (1987), many writers are considered to be 'unskilled' or 'novice' writers even in their first language, and therefore may not have developed effective strategies which they can transfer to the learning of a new language. Similarly, even skilled L1 writers may not 'automatically transfer the strategies they learn in one context to a different situation' (Rubin, Chamot, Harris, and Anderson, 2007: 147). L1 strategies may also have become proceduralized to the point where students may not be consciously aware of them, therefore further hindering the potential for transfer (Perkins and Salomon, 1988).

The study at the heart of this paper therefore initially emerged from a hypothesis that if the use of writing strategies is explicitly developed within the FL classroom, then it seems logical that this knowledge could not only benefit FL writing tasks, but may also positively affect L1 writing. While studies into such reverse transfer in writing are limited, some evidence of this has been detected by Berman (1994), Kecskes and Papp (2000) and Kobayashi and Rinnert (2007) in relation to essay organization skills, use of syntactic structures and transfer of rhetorical features respectively. 
Although not situated within the framework of strategy research, the findings from these studies suggest that FL teachers, who are able to focus more explicitly on the development of language learning strategies, are in a unique position to contribute to an overall improvement in writing standards. As stated by Pomphrey (2000: 278):

The act of consciously learning a language in the classroom implies a distancing of the self from the usual unconscious habits of everyday communication. This means that explicit knowledge about language as a system is likely to be more easily extracted from the foreign language learning experience than from learning which takes place in the L1.

The aim of this paper, then, is to provide a framework for the development of a cross-curricular intervention of strategy-based instruction between L1 and FL secondary school classrooms. The motivation behind this intervention was to bring together approaches to writing pedagogy among English and FL teachers in order to help learners to become more effective strategy users and in turn, more proficient writers in both language contexts. This paper will consider:

1. The factors which contribute to the design of a strategy-based, cross-curricular intervention in writing pedagogy;

2. The development and implementation of the intervention;

3. The effects of a cross-curricular intervention on the development and transfer of writing strategies in and between the L1 and FL.

\section{Overall research design}

The study which led to the development of the framework presented in this paper involved a classroom intervention of explicit strategy-based instruction which was delivered first in the German foreign language classroom, and later also in the English classroom of a Year 9 (age 13-14) mixed ability class in a secondary school in England (referred to as the Experimental Group). A parallel mixed ability class in the same year group was also designated as a Control Group in order to help to establish the extent to which any changes which took place could be attributed to the strategy intervention. This year group was chosen as it is the final year of compulsory FL learning in school, and therefore the students represented a wider range of proficiency levels and attitudes towards the subject than those who self-select to continue the subject further. All students studied both German and French as foreign languages. The overall research design is outlined in Figure 1 and further details of the study can be found in Forbes (2016). 


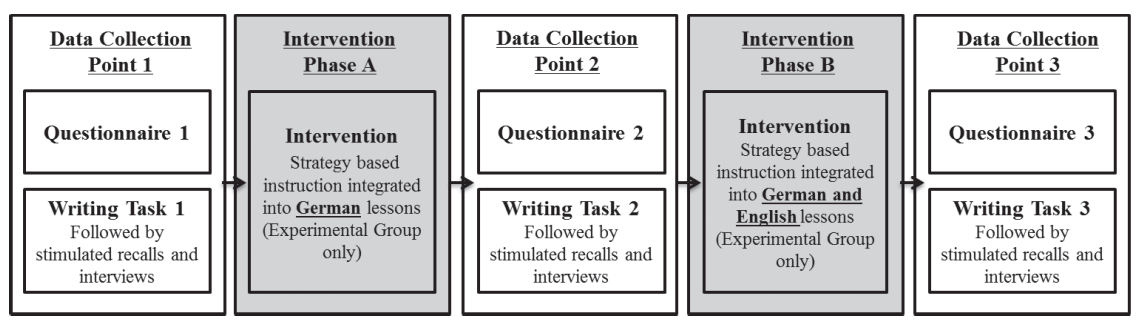

Figure 1: Overview of research design

The data collected in the first stage of the process was used to identify existing conceptualizations of and approaches to writing in English and the FLs through questionnaires, writing tasks and interviews. This information was then used to develop an intervention of SBI to be carried out in the German classroom over the course of four months. The SBI was designed to be integrated into existing schemes of work and involved the introduction of tasks and activities to aid the planning, monitoring and evaluation of written work and to encourage students to reflect on and assess their personal learning strategies and approaches; full details of this are presented below. Then, another set of measures were taken to investigate whether or not this explicit focus on strategy use in German lessons affected students' approach to writing in German, and also whether any of the learners transferred these strategies to their French or English writing tasks without any explicit encouragement to do so. During the next phase of the intervention, the SBI continued in the German classroom, however was also explicitly reinforced in the English classroom. Similar activities and resources were used by both teachers in order to encourage learners to transfer the skills and strategies they developed in one curriculum area to another. A third and final set of data was then collected to explore any further changes which took place as a result of this additional explicit instruction in both the L1 and FL classrooms.

This study was characterized by its longitudinal design as it took place over the course of one academic year and incorporated three data collection points, as outlined in Figure 1. The longitudinal nature of the study was key in measuring change and accounting for complexity; as suggested by Kobayashi and Rinnert (2007: 87), 'there are benefits to be gained from engaging in longitudinal research on beliefs and strategies since this research design can help us capture the dynamics of beliefs and strategies over time'.

Having provided a brief overview of the research design, the following sections will in turn explicate the rationale behind the factors which it was 
necessary to take into account when designing such a study, the implementation of the intervention itself, and will draw on data from the above study to illustrate the effects of such a programme of instruction.

\section{Factors which contribute to the design of a strategy-based, cross-curricular intervention in writing pedagogy}

This section will consider three key factors which were taken into account before developing such an intervention, namely: the school system; teacher and student conceptualizations of writing in each language; and existing approaches to writing.

\section{School systems}

As outlined above, at the level of the national curriculum the teaching of English and FLs are often treated very differently in schools in England. However, before developing any form of cross-curricular intervention, it is important to consider how this is enacted within an individual school context by examining school policies and schemes of work. In the case of the current study, the English and FL departments were housed in separate buildings and the teachers in one department were largely unaware of the approaches to writing adopted in the other. An examination of school-wide and departmental policies contained no reference to making links between different language contexts.

In terms of task types and expectations, students aged 11-14 in English were expected to produce narrative-style tasks, which includes creative writing, alongside more analytical tasks such as essays on novels or plays. In FLs, however, where students were operating at a significantly lower level of proficiency, writing exercises predominantly took the form of narrative-style tasks related to specific topics, such as writing about oneself or a past holiday. Yet when looking at the mark schemes used in each subject, some similarities emerged in terms of overall aims and expectations. Teachers in both subject areas focused on both content and accurate use of language; while English teachers looked for writing which was 'engaging' and made 'proper use of structure', FL teachers also sought evidence of a 'sound ability to convey information clearly' and a 'well organized structure. Both mark schemes also highlighted the importance of the accurate use of spelling, punctuation and grammar. It seems therefore that teachers in both contexts were working towards shared aims and goals in writing, even if such links were not made explicit.

Nevertheless, the selection of appropriate writing tasks which would enable links to be drawn between writing in the various languages remained 
a challenge in the current study. As it would not have been feasible to adapt the same task to all of the languages given the discrepancy between L1 and FL proficiency, it was deemed suitable to ensure that each of the tasks was of the same style, i.e. a narrative-style task. Examples of this include a piece of travel writing in English, a text about hobbies in German and a description of a family in French.

\section{Teacher and student conceptualizations of writing in each language}

While departmental documentation provides important information about policies and priorities, it is also crucial to consider students' and teachers' own perceptions of writing in each of the languages. In the current study this was done through a student questionnaire and interviews with both students and teachers.

The aim of the questionnaire was to establish and then track students' conceptualizations of writing in each language and their perceptions of their performance relating to different aspects of writing. As highlighted by Yang (1999), there may exist a cyclical relationship between learners' beliefs and strategy use, whereby appropriate strategy use may lead to an enhanced self-perception of language proficiency, which in turn may increase strategy use. It is therefore important to give due consideration to student beliefs. Using a four-point Likert scale the students were asked to rate the importance of and their performance in a range of criteria, such as 'planning your work', 'organizing a text', 'overall accuracy' and 'revising your work'. However, it is recognized that 'questionnaires only provide reports of what people say they think or do' (Hyland, 2002: 166) and therefore they were followed up by interviews with 12 case study students in order to further explore their responses. These students were chosen to represent a mix of gender and performance levels. The interviews were semistructured and aimed to explore why students had selected particular responses and to elicit examples.

It is worth noting that at the beginning of the study the students perceived writing in German and French in a very similar way, yet had distinct conceptualizations of writing in the L1 and FLs. This was especially evident in relation to: the type of tasks set, which were viewed as more restrictive and confining in the FLs, the expectations in both contexts and their level of proficiency. One girl, for example, commented in the interview:

I think I see them as quite different, cause when I'm writing in, yeah, like when I'm writing in French and German like, I just feel like I'm being marked on like, like, spelling and like words and stuff, but with English it is more about what you're writing, so I do think they're quite different and I treat them differently. 
Interviews were also conducted with the English and FL teachers in order to explore similar themes from a pedagogical perspective. Teachers were asked about the emphasis placed on developing writing skills in their particular language and the approach they took to teaching these. They were also asked to comment on the importance of key aspects based on the student questionnaires, such as planning, use of resources and checking over work. In this particular study, the teacher interviews revealed a lack of awareness about the way in which writing was taught or viewed outside of their particular subject area. Interestingly, both teachers and students shared distinct conceptualizations of L1 and FL writing, suggesting perhaps that if teachers can align their practices in a more cross-curricular way, this may also help students to make connections and transfer skills between their different languages. The information gathered about the perceptions of both teachers and students was essential for developing the intervention, as it highlighted not only potential areas for cross-over but also areas of difference which may require more explicit connections to be made.

\section{Existing approaches to writing}

It was also crucial to gather more objective data about students' existing approaches to writing in each language. As emphasized by Macaro (2001: 108), 'intervention without a prior stage of strategy elicitation of those particular learners (and therefore description) is invalid'. In order to capture information about strategy use, the students were asked to complete a narrative-style writing task in each of the three languages on a specially designed writing strategy task sheet. This was based on a method used by Macaro (2001) and was designed to capture students' pre-task planning, the use of resources and problem-solving strategies while writing (by asking students to use underlining and the notes section of the margin), and included some post-task questions about the evaluation process, such as whether they checked over their work and what they checked for.

As the task sheets required students to report their strategy use relating to a specific and contemporaneous task, it was felt that this would provide a more accurate reflection of their behaviour than a more general questionnaire. Additionally, students were given the space to add their own thoughts and notes and were not restricted to selecting from a predetermined list. The use of the task sheets allowed for the writing tasks to be completed simultaneously by the whole class under normal classroom conditions in an authentic environment, in line with a sociocognitive perspective, rather than individually conducting think aloud protocols with each student in isolation. Evidence of strategy use was coded into several 
categories: planning, monitoring, errors and error correction and evaluation. Stimulated recall interviews were then conducted with the 12 case study students in order to gather more in-depth data about the strategies used.

Key patterns emerged from this analysis which shaped the development of the intervention. As suggested by the interviews, evidence from the writing tasks confirmed that at the beginning of this study, students approached writing differently in English and the FLs. For example, students were much more likely to engage in any form of planning in English than in German or French and to produce much longer plans and use a wider range of planning strategies in English. While a common approach in English was for students to draft all or part of their work during the planning phase, in German and French very little written planning was produced and where there was some, this was generally limited to a small number of bullet points of items of vocabulary. Students similarly identified a much wider range of evaluation strategies in English, even though they were aware that they were much more likely to make errors when writing in German or French. Given the difference in students' baseline approaches to writing in English and in the FLs at the beginning of the study, it seemed as though they were not necessarily transferring their L1 writing strategies automatically to a FL. A key aim of the subsequent intervention therefore, was to encourage students to reflect on and make connections between the strategies they use when writing in different languages.

\section{Developing and implementing the intervention}

The pedagogical intervention involved the introduction of tasks and activities to aid students in planning, monitoring and evaluating their written work and to encourage them to reflect on and develop their individual learning strategies. This section will first outline some key factors to consider in relation to the implementation of SBI and will then provide an overview of the main stages in the intervention drawing on examples from the current study.

\section{The implementation of strategy-based instruction}

When implementing a programme of SBI it is important to consider several factors:

- Whether instruction should be integrated into normal classroom teaching or taught separately; 
- Whether strategies should be explicitly taught or implicitly embedded into activities and materials;

- Whether strategies in FL classrooms should be taught through the target language or the L1.

In this study, the decision was made to integrate the instruction into normal classroom teaching so as to make it relevant and so as not to disrupt students' learning. In addition, references to strategies were made explicit as 'it is believed that this metacognitive knowledge will facilitate transfer of the strategies to new tasks and will assist students toward autonomous use of the strategies' (O'Malley and Chamot, 1990: 184), which is in line with later findings by Macaro (2001) and Cohen (2011). From a transfer of learning perspective (Perkins and Salomon, 1988), explicit instruction has also been highlighted as crucial for stimulating transfer between tasks or contexts which are superficially different (referred to as high road transfer), such as engaging in writing in English compared to a foreign language. In order to promote transfer, instruction should therefore not only clearly address how to use a particular strategy or skill, but also when to use it (Perkins and Salomon, 1988: 24). In addition, the decision was made to conduct the SBI in English, even in the FL classroom, due primarily to the low level of students' German. However, it was also felt that if the SBI was conducted in the same language across each of the subjects and if terminology remained relatively consistent, it may be easier for students to make connections and to transfer the strategies between contexts.

\section{Strategy-based instruction}

A range of models of explicit SBI have been proposed within the second language education literature (see Chamot, Barnhardt, El-Dinary, and Robbins, 1999; Grenfell and Harris, 1999; Macaro, 2001; Oxford, 2017). However, they all follow a similar sequence of four steps which forms the basis for the development of the current pedagogical intervention (Figure 2). These steps are not necessarily linear, but should instead be considered as recursive, 'so that teachers and students always have the option of revisiting prior instructional phases as needed' (Chamot, 2008: 271). The models also share a similar aim; to encourage students to become more metacognitively aware language learners and more autonomous strategy users. This section will consider the rationale behind each of the four steps in turn, and provide examples from the current study to exemplify how they were incorporated into both the English and FL classrooms. 


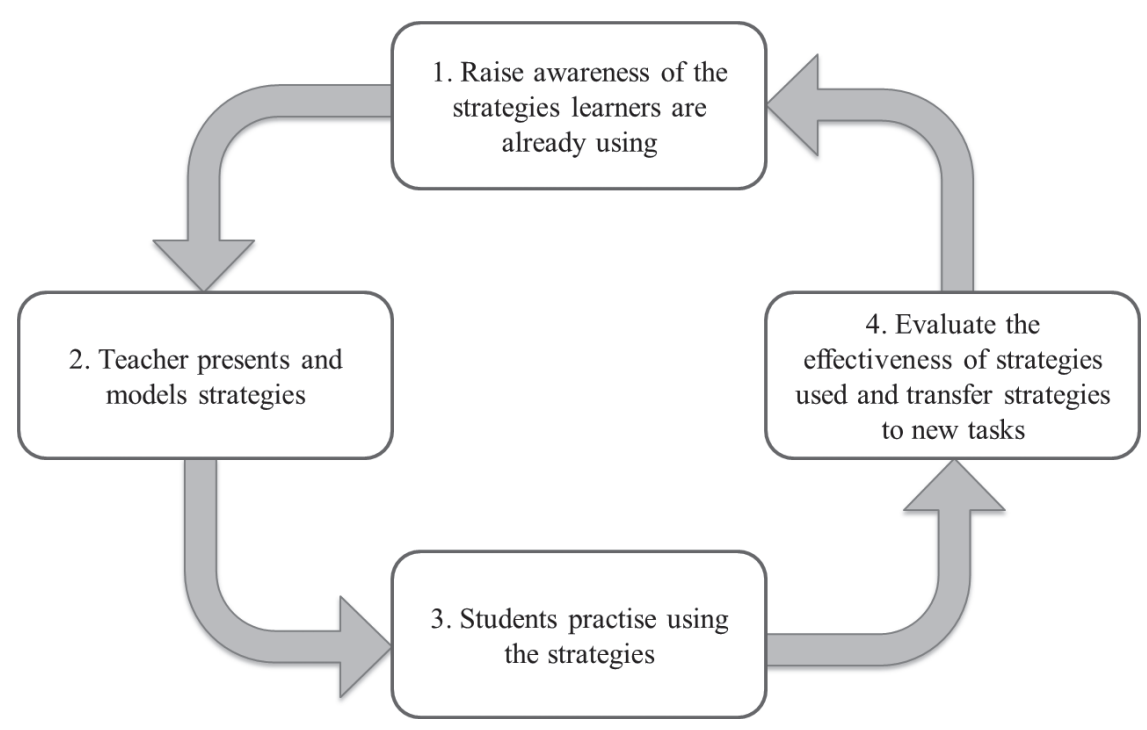

Figure 2: Stages of the SBI cycle

\section{Step 1: Raise awareness of the strategies learners are already using}

It is widely recognized that an important step in any form of strategy research 'is to help learners recognise which strategies they already use' (Cohen, 1998: 69) and this furthermore serves a pedagogical purpose as 'a foundation for deciding which strategies to teach' (Oxford, 2011: 140). This is particularly important when working across different curriculum subject areas. As noted above, both students and teachers have different perspectives and priorities when writing in English and FLs and they should be encouraged to reflect on this. Similarly, given students' higher level of proficiency in their mother tongue it is likely that they will be less consciously aware of their strategy use in this language. Paradoxically therefore, such elicitation and awareness-raising may prove more difficult in the L1 classroom.

In this study, for example, the initial German writing task, which was completed by all of the participants at the beginning of the year, was used as a stimulus for a whole-class discussion about which strategies students used and how they used them. The teacher asked for students to raise their hand if they had, for example, done any pre-task planning, used a dictionary, asked for help or checked over their work afterwards. This enabled learners to see that they and their peers had utilized a range of different strategies to complete the task. Students then spent several minutes discussing their task in pairs and were asked to explain to each other some of 
the strategies they used, why they used them and whether they found them helpful. The students and teacher then co-constructed a list of some of the existing writing strategies used by the class, which included, for example, planning ideas, looking up keywords, using their textbook, asking for help, re-reading their work and checking spelling. This was later mirrored in the English classroom during the second phase of the intervention. This process not only provided a starting point for the development of the intervention, but also raised students' awareness of what a strategy is and what they do. This type of awareness-raising activity was revisited regularly throughout the course of the year in both the German and English classrooms to encourage learners to continually monitor and develop their strategy use.

\section{Step 2: Teacher presents and models strategies}

The second step involved the teacher presenting, modelling and explaining a range of writing strategies. Not all strategies were presented at once, but were grouped into planning, monitoring and evaluation strategies and were built up gradually. Figure 3 provides an overview of the main strategies focused on within each group. When the SBI was introduced into the English classroom, similar resources and terminology were used in order to encourage the students to think about transferring relevant strategies from one context to another. Inevitably there were some strategies which were more closely linked with one subject, such as the use of backtranslating as an evaluation strategy, however on the whole the majority were relevant to both the L1 and FL.

Throughout the process of presenting strategies, the teacher was always explicit about the rationale behind using the strategy; as underlined by Cohen (1998: 93), 'it is necessary for teachers to inform their learners fully as to the strategies that they are being taught and the value and purpose of employing these strategies'. In order to present the strategies, the teacher modelled them clearly by thinking aloud during an activity in order to reveal to students their thought processes and strategies used.

However, it was also important to make clear to students that they would not necessarily find every strategy helpful, nor would every strategy be appropriate for every task. Within a sociocognitive framework, teachers are often recognized as 'co-authors' of students' writing (Prior, 2006: 58) which allows for the 'co-construction of learning strategies' (Collins, 1998: 48). Therefore, it is important for teachers to avoid any attempts to impose the 'right' strategies on learners and instead to provide them with a range of strategies along with the skills to be able to assess which strategies would aid them as an individual to complete a particular task.

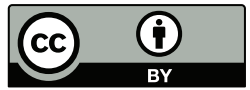




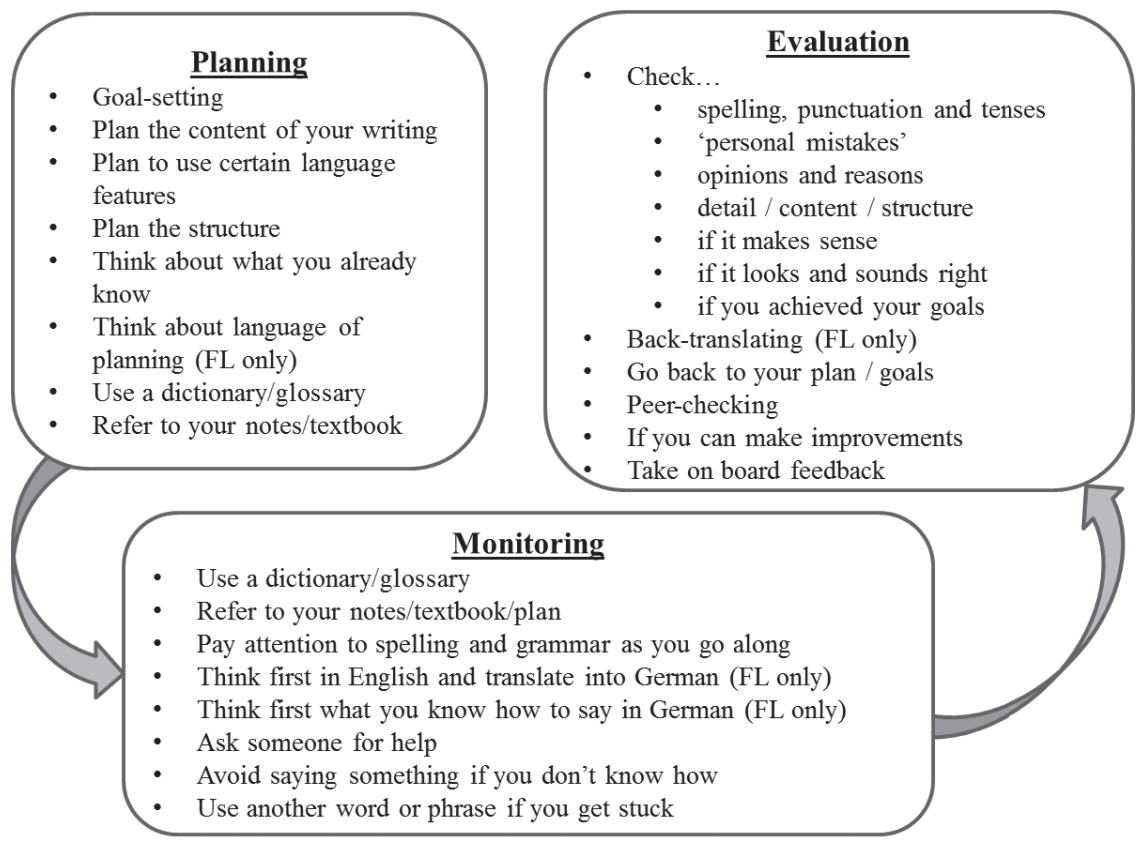

Figure 3: Overview of the main writing strategies developed

\section{Step 3: Students practise using the strategies}

The third step of the process then provided students with the opportunity to practise the strategies for themselves across a range of tasks. Initially this was done via scaffolding sheets which allowed for guided practice. Examples of activities introduced in both the German and English classroom are outlined below.

Planning activity. Links between the development of effective planning strategies and improvement in the quality of writing have been reported in a number of studies in both the FL (e.g. Sasaki, 2002) and L1 contexts (e.g. De La Paz and Graham, 2002). A scaffolding sheet was therefore designed to help students plan for a German writing task on the topic of school. Students were guided to set themselves goals for the task, consider the main content ideas and language features they would include (such as particular verb tenses or structures), find key words and phrases in German, and to think about the overall structure of their text. A similar sheet was used to help them to plan for an English creative writing task. While in this case students were not asked to find key phrases in the same way as 
they had done for German, they were prompted to think about using particular language features such as alliteration, metaphors and a variety of adjectives.

Evaluation activity. Following a German writing task on holidays, students were given a scaffolding sheet to guide them through checking their work. This asked whether they had specifically checked for a range of features, such as spelling, relevance and verb tenses, and also asked them to indicate whether they had made any changes as a result of checking their work. This aimed to encourage students to more actively engage with checking over their work and, combined with feedback from the teacher, enabled them to see which aspects of evaluation they perhaps needed more practice with. A similar sheet was used in the English classroom, however was adapted slightly to capture aspects of particular relevance to this context. For example, following an argumentative essay task students were additionally asked to reflect on their use of persuasive language.

'Moving on' strategies. As suggested by Macaro (2001: 219), strategy training should go beyond the planning, monitoring and evaluation stages and should also incorporate what are referred to as 'moving on' strategies, which 'update the mental models of the target language as a result of feedback'. This was incorporated into the current study by means of an error correction activity in German. This aimed to encourage students to engage more actively with teacher feedback following a writing task, and to enable them to feed this forward into future tasks by improving their ability to detect and correct errors. Errors were underlined and students were asked to identify the 'type' of error and then to correct it. Students were encouraged to use this to set targets for subsequent activities. In English, students were similarly encouraged to engage with feedback and to set targets for subsequent tasks. While the same principles applied, due to the nature of the tasks this more frequently tended to be at the level of content or structure for English rather than at word or sentence level.

Removing scaffolding. In line with other frameworks for SBI (e.g. Chamot, 2005; Grenfell and Harris, 1999; Macaro, 2001) the resources which explicitly guided students through a task were gradually removed and they were encouraged to select and combine the strategies they wanted to use more independently. After students had been given the opportunity to practise their strategy use on several occasions using the guided task sheets, these were then replaced with summary sheets providing an overview of strategies. Students were encouraged before each task to take a moment 
to reflect on which strategies they would use and what they found useful afterwards. This was then reduced further to a summary sheet similar to Figure 3 which students kept in their books and which was referred to progressively less by the L1 and FL teachers.

\section{Step 4: Evaluation of the effectiveness of strategies used and transfer of strategies to new tasks}

The fourth step in the cycle of SBI involved the evaluation of the effectiveness of the strategies used and the subsequent transfer of strategies to different tasks and ultimately, to different subjects. The act of evaluating is a metacognitive strategy in itself, and forms a valuable part of SBI. Learners should be able to monitor and assess the usefulness of a particular strategy and then decide whether or not it is appropriate. Such metacognitive engagement with their learning facilitates the transfer of strategies. Students were encouraged to reflect systematically on their strategy use through whole class and small group discussions led by the teacher throughout the intervention, and also individually by means of the strategy evaluation sheets discussed above. In line with Graham and Macaro (2007), feedback was provided to students, not just on the accuracy of the finished written product itself, but also on their strategic approach to writing tasks, with a view to helping them develop their strategy use; this took the form of verbal feedback to students in class while they were working on a task and occasionally written comments on their work suggesting which strategies they should try. Teacher feedback on strategy use is instrumental in helping learners to reflect more deliberately on their approach to writing with a view to helping them to gradually develop the metacognitive skills they need to engage with and expand on their strategy use more independently (Oxford, 2017). Schunk and Schwarz (1993: 339) have similarly highlighted that 'strategy feedback promotes achievement outcomes and strategy use better than strategy instruction alone'.

\section{The effects of a cross-curricular intervention of SBI}

While the primary focus of this paper is the development of the intervention itself, it is also worth commenting on the key findings which emerged from the empirical study in order to demonstrate the effect of such an approach on students' development and transfer of writing strategies within and between the L1 and FL classrooms. While space only allows for a summary of the results here, further details can be found in Forbes (2018b) and Forbes and Fisher (2018). 


\section{Strategy development and transfer}

As a result of the intervention of SBI, there was evidence to suggest that, in comparison to the Control Group, the Experimental Group students developed both the quantity and quality, or effectiveness, of their strategy use. This occurred to some extent across all languages; however it was most evident in German, which is not surprising given that this was the context in which students received explicit strategy instruction for the longest period of time. Key findings are as follows:

- Planning: There was an increase in engagement in pre-task planning among the Experimental Group students in both German and French after the first phase of SBI and in both FLs there was also an increase in the planning of content items, language features and goal setting following Phase A of the intervention in the German classroom. In English, although the SBI did not seem to affect the number of students engaging in written planning, which was already high to begin with, it did seem to positively impact the quality of their planning, particularly in relation to the planning of language features, style and goal-setting. Even though most of these changes in English occurred following the explicit phase of SBI in the English classroom, it seems that even after Phase A students were beginning to use a wider range of strategies, which is perhaps indicative of some level of FL-L1 transfer.

- Problem-solving strategies: There was evidence of the Experimental Group students shifting problem-solving strategies, such as dictionary use, to the planning stage, rather than disrupting the writing process by engaging in this during the task itself.

- Accuracy: Another key area where the SBI impacted students' strategy use was in relation to the number of errors made and corrected. The Experimental Group students made fewer errors over time in all subjects and this was significantly less than the Control Group in German at Point 3 and in English at both Points 2 and 3. Although not a strategy in itself, such an increase in levels of accuracy provides an objective measure of a range of monitoring and evaluation strategies used successfully by students. In particular, they took an increasingly thorough and more focused approach to checking over their work, especially following Phase A in the FLs and Phase B in English.

- Attainment: Such development in students' strategy use also corresponded to an improvement in achievement in the writing tasks. While there was no significant difference between the writing task 
scores of the Experimental Group and Control Group students at the beginning of the study, at Points 2 and 3 in German and at Point 2 in English the Experimental Group scored significantly higher than the Control Group. In addition, over time the mean scores of the Experimental Group improved consistently across each of the three languages.

In terms of strategy transfer, there was some evidence following Phase A of the intervention to suggest that students transferred some strategies developed in the German classroom to English tasks without any explicit encouragement to do so. This was particularly evident in relation to the quality of planning, as indicated by an increase in both the frequency and range of planning strategies used by the Experimental Group, and in an improvement in accuracy, as demonstrated by both a decrease in errors made and an increase in errors self-corrected. Most changes in English, however, occurred following Phase B of the intervention, when the links between strategy use in the L1 and FL classroom were made explicit, underlining the potential benefit for students of cross-curricular collaboration among language teachers. Following Phase B of the intervention there was a further increase in the number and range of planning strategies used by the Experimental Group in English, further improvement in the accuracy of their writing and an increase in the number and range of evaluation foci identified by students.

\section{Conceptualizations of writing}

In addition to patterns of strategy development and transfer, this study also focused on students' perceptions of writing in the different language classrooms. As noted above, at the beginning of the study the students had distinct conceptualizations of writing in the L1 and FLs as reported in the questionnaires and interviews. However, over the course of the intervention the Experimental Group students' views both of what they considered to be important and their own performance in L1 and FL writing seemed to converge, particularly in terms of an increase in importance given to criteria such as planning, revising and accuracy in all subjects. This was especially striking when compared to the Control Group where views of the two language contexts conversely seemed to be diverging.

Over time, the Experimental Group students also increasingly viewed some aspects of their approach to writing as cross-linguistic, rather than as specific to L1 or FL contexts, highlighting further the potential for encouraging the transfer of skills and strategies between languages. One boy, for example, commented in the final interview: 
I think they've got much closer now, doing these types of things, because you're planning more, you're using the same sort of sheets so it kind of shows you that they do relate to each other, so you can use the same things, so like reading through afterwards, checking for spelling and structures, they're all the same, they're all in French, German and in English.

There may therefore be a link between the converging patterns of L1 and FL strategy development and students' converging conceptualizations of the two contexts; as connections between the two contexts became more apparent over time, this in turn may have facilitated transfer.

\section{Limitations and reflections}

Due to the mentalistic nature of metacognition and strategic thought processes, during the data collection process it was necessary to rely heavily on self-report data, either in written form on the writing task sheets or verbally through the interviews. As such, students could only report on strategies that they were consciously aware of using, and there is therefore a risk that some of their thought processes had become proceduralized and were not accessible for report. It is important to acknowledge, therefore, that the majority of data collected can only be considered as learners' perceptions of their strategy use. As stated by Grenfell and Harris (1999: 54): 'it is not easy to get inside the "black box" of the human brain and find out what is going on there. We work with what we can get, which, despite the limitations, provides food for thought.' Similarly, it is also important to be aware of the possibility that the students may have simply reported what they felt they were supposed to report, given the focus of the intervention and the particular prompts used in the writing task sheets and interviews. It could therefore be argued that any increase in their reported use of strategies was simply the result of raised awareness of use, or ideas being planted in the minds of the participants. Yet as Cohen, Weaver and Li (1998: 147) state, 'the power of suggestion alone is not usually enough to produce strategy use.' Furthermore, exactly the same prompts and elicitation techniques were used with the control group students, where the same trends and results were not observed.

\section{Discussion and conclusion}

The process of developing such a strategy-based, cross-curricular approach to writing pedagogy, along with the resulting findings, suggest that while a programme of SBI is beneficial within a particular language context, effects are most powerful when there is collaboration between L1 and FL teachers. Gunning, White and Busque (2015) similarly found that when the first 
language and second language (L2) teachers in their study collaborated in the teaching of reading strategies at a school in Francophone Canada, the students became more effective at self-monitoring their reading in both languages. In relation to writing, Kobayashi and Rinnert (2008: 20) also commented with regard to their study with undergraduate students that 'the interaction between intensive L1 and L2 training led to greater effects than either of the separate kinds of training alone would have allowed us to predict, perhaps because of the greater confidence it generated for both L1 and L2 writing. Such positive interaction between the two language contexts reinforces the potential benefit of collaboration.

Yet, while there is evidence to suggest that collaboration between L1 and FL teachers in the teaching of writing strategies can lead to positive benefits for the students, it is also important to acknowledge the challenges and potential barriers to such collaboration arising from the difference between the language contexts. At a curriculum level, Harris (2006) noted the distinction between the aims and objectives of English and FL teachers in the UK context, a gap exacerbated by government policies and a lack of time to plan cross-curricular activities. As such, teachers are often unfamiliar with the curriculum or specific terminology used in another subject area and any potential collaboration may also be hindered by the L1 teacher's limitation in a FL.

At an organizational level, Perkins and Salomon (1988) similarly commented that the way in which certain skills are partitioned off from each other in schools can impede students' ability to transfer them from one subject area to another. These considerations contribute to a difference in the way in which learners and teachers view each subject at a personal level. As shown above, at the beginning of this process both groups conceptualized writing in the L1 and in the FLs quite differently. This is in line with findings from a study conducted by Haukås (2015), which revealed that Norwegian teachers of L3 French, German or Spanish conceptualized the learning of the L3 as being completely different from the learning of L2 English. As a result, they rarely focused on the transfer of learning strategies between these subjects. Yet interestingly, they strongly believed that collaboration across languages could enhance students' learning, and results from the current study confirm that such collaboration can indeed positively influence students' attainment in writing. The implementation of an explicit, cross-linguistic programme of instruction for developing writing, such as the one outlined in this paper, may therefore provide the necessary framework for encouraging connection-making and transfer among both students and teachers.

In the final analysis, while De Angelis and Jessner (2012: 65) called for a 'multilingual approach to the study of writing development', I would extend 
this further and argue for a multilingual approach to the teaching of writing in schools. As highlighted by Burley and Pomphrey (2003), both English and FL teachers in the context of UK secondary schools are teachers of language and as such, should share some common aims and practices. Writing, after all, is a crucial skill which permeates the entire school curriculum, and evidence from the current study suggests that some form of coordination between L1 and FL teachers in relation to writing strategies can be mutually beneficial for students' overall writing development in both contexts.

\section{Acknowledgements}

I am grateful to the ESRC for providing funding for the $\mathrm{PhD}$ study from which this paper is drawn. I also wish to thank my supervisor, Dr Linda Fisher for her continued support and feedback and the anonymous reviewers for their useful comments and suggestions on this paper.

\section{About the author}

Dr. Karen Forbes is a Lecturer in Second Language Education in the Faculty of Education, University of Cambridge. Her current research interests include the development and transfer of language learning strategies, the language development of students who speak English as an additional language in schools and the influence of multilingual identity in foreign language learning.

\section{References}

Ardasheva, Y., Wang, Z., Adesope, O. O., and Valentine, J. C. (2017). Exploring effectiveness and moderators of language learning strategy instruction on second language and self-regulated learning outcomes. Review of Educational Research 87 (3), 544-582. https://doi.org/10.3102/0034654316689135

Bai, B. (2015). The effects of strategy-based writing instruction in Singapore primary schools. System 53, 96-106. https://doi.org/10.1016/j.system.2015.05.009

Bereiter, C. and Scardamalia, M. (1987). The Psychology of Written Composition. Hillsdale, NJ: Lawrence Erlbaum Associates Inc.

Berman, R. (1994). Learners' transfer of writing skills between languages. TESL Canada Journal/Revue TESL Du Canada 12 (1), 29-46. https://doi.org/10.18806/tesl.v12i1.642

Bialystok, E. (1978). A theoretical model of second language learning. Language Learning 28 (1), 69-83. https://doi.org/10.1111/j.1467-1770.1978.tb00305.x 
Bouwer, R., Koster, M., and van den Bergh, H. (2018). Effects of a strategy-focused instructional program on the writing quality of upper elementary students in the Netherlands. Journal of Educational Psychology 110 (1), 58-71. https://doi.org/10.1037/edu0000206

Burley, S. and Pomphrey, C. (2003). Intercomprehension in language teacher education: A dialogue between English and Modern Languages. Language Awareness 12 (3-4), 247-255. https://doi.org/10.1080/09658410308667080

Chamot, A. U. (2005). Language learner strategy instruction: Current issues and research. Annual Review of Applied Linguistics 25, 112-130. https://doi.org/10.1017/S0267190505000061

Chamot, A. U. (2008). Strategy instruction and good language learners. In C. Griffiths (Ed.), Lessons from a Good Language Learner, 266-281. Cambridge: Cambridge University Press. https://doi.org/10.1017/CBO9780511497667.024

Chamot, A. U., Barnhardt, S., El-Dinary, P., and Robbins, J. (1999). The Learning Strategies Handbook. White Plains, NY: Addison-Wesley.

Cohen, A. D. (1998). Strategies in Learning and Using a Second Language (1st ed.). Harlow: Longman.

Cohen, A. D. (2011). Strategies in Learning and Using a Second Language (2nd ed.). Harlow: Longman.

Cohen, A. D., Weaver, S. J., and Li, T. Y. (1998). The impact of strategies-based instruction on speaking a foreign language. In A. D. Cohen (Ed.), Strategies in Learning and Using a Second Language. Harlow: Longman.

Collins, J. L. (1998). Strategies for Struggling Writers. New York: Guilford Press. https://doi.org/10.2307/358940

Cumming, A. (1989). Writing expertise and second language proficiency. Language Learning 39 (1), 81-141. https://doi.org/10.1111/j.1467-1770.1989.tb00592.x

Dan, M. (2017). An empirical study on writing strategies: Training mode in CSL teaching. Chinese as a Second Language Research 6 (1), 175-200.

De Angelis, G. and Jessner, U. (2012). Writing across languages in a bilingual context: A dynamic systems theory approach. In R. M. Manchón (Ed.), L2 Writing Development: Multiple Perspectives, 47-68. Berlin: Walter de Gruyter, Inc. https://doi.org/10.1515/9781934078303.47

De La Paz, S. and Graham, S. (2002). Explicitly teaching strategies, skills, and knowledge: Writing instruction in middle school classrooms. Journal of Educational Psychology 94 (4), 687-698. https://doi.org/10.1037/0022-0663.94.4.687

De Silva, R. and Graham, S. (2015). The effects of strategy instruction on writing strategy use for students of different proficiency levels. System 53, 47-59. https://doi.org/10.1016/j.system.2015.06.009

Flower, L. and Hayes, J. R. (1981). A cognitive process theory of writing. College Composition and Communication 32 (4), 365-387. https://doi.org/10.2307/356600

Forbes, K. (2016). Cross-Linguistic Transfer of Foreign Language Writing Strategies: Developing First and Foreign Language Writing Through Metacognitive Strategy Use (PhD thesis). University of Cambridge, Cambridge, UK. 
Forbes, K. (2018a). 'In German I have to think about it more than I do in English': The foreign language classroom as a key context for developing transferable metacognitive writing strategies. In Å. Haukås, C. Bjørke, and M. Dypedahl (Eds), Metacognition in Language Learning and Teaching. New York: Routledge.

Forbes, K. (2018b). The role of individual differences in the development and transfer of writing strategies between foreign and first language classrooms. Research Papers in Education. https://doi.org/10.1080/02671522.2018.1452963

Forbes, K. and Fisher, L. (2018). Strategy development and cross-linguistic transfer in foreign and first language writing. Applied Linguistics Review. https://doi.org/10.1515/applirev-2018-0008

Graham, S. and Harris, K. R. (2003). Students with learning disabilities and the process of writing: A meta-analysis of SRSD studies. In H. L. Swanson, K. R. Harris, and S. Graham (Eds), Handbook of Learning Disabilities, 323-344. New York: Guilford Press.

Graham, S., Harris, K. R., and Mason, L. (2005). Improving the writing performance, knowledge, and self-efficacy of struggling young writers: The effects of self-regulated strategy development. Contemporary Educational Psychology 30 (2), 207-241. https://doi.org/10.1016/j.cedpsych.2004.08.001

Graham, S. and Macaro, E. (2007). Designing Year 12 strategy training in listening and writing: From theory to practice. Language Learning Journal 35 (2), 153-173. https://doi.org/10.1080/09571730701599203

Grenfell, M. and Harris, V. (1999). Modern Languages and Learning Strategies: In Theory and Practice. London: Routledge.

Griffiths, C. (2013). The Strategy Factor in Successful Language Learning. Bristol: Multilingual Matters Ltd. https://doi.org/10.21832/9781847699428

Gunning, P., White, J., and Busque, C. (2015). Enhancing pedagogy through first and second language teacher collaboration. Paper presented at the meeting of the American Association of Applied Linguistics, Toronto, Canada.

Harris, V. (2006). Language learning strategies across the curriculum: Government policy and school practice. In British Educational Research Association Annual Conference. University of Warwick: Education-Line. Retrieved from http://www.leeds.ac.uk/educol/documents/160889.htm

Haukås, Å. (2015). Teachers' beliefs about multilingualism and a multilingual pedagogical approach. International Journal of Multilingualism. https://doi.org/10.1080/14790718.2015.1041960

Hayes, J. R. and Flower, L. (1980). Identifying the organization of writing processes. In L. W. Gregg and E. R. Steinberg (Eds), Cognitive Processes in Writing: An Interdisciplinary Approach, 3-30. Hillsdale, NJ: Lawrence Erlbaum Associates Inc.

Hyland, K. (2002). Teaching and Researching Writing. London: Pearson Education. Jones, C. S. and Tetroe, J. (1987). Composing in a second language. In A. Matsuhashi (Ed.), Writing in Real Time, 34-57. New York: Addison-Wesley.

Kecskes, I. and Papp, T. (2000). Foreign Language and Mother Tongue. Mahwah, NJ: Lawrence Erlbaum Associates Inc. https://doi.org/10.4324/9781410606464 
Kobayashi, H. and Rinnert, C. (2007). Transferability of argumentative writing competence from L2 to L1: Effects of overseas experience. In M. Conrick and M. Howard (Eds), From Applied Linguistics to Linguistics Applied: Issues, Practices, Trends. Proceedings of the 2006 BAAL/IRAAL Conference (Cork, September) (Vol. 22), 91-110. London: British Association for Applied Linguistics.

Kobayashi, H. and Rinnert, C. (2008). Task response and text construction across L1 and L2 writing. Journal of Second Language Writing 17 (1), 7-29. https://doi.org/10.1016/j.jslw.2007.08.004

Macaro, E. (2001). Learning Strategies in Foreign and Second Language Classrooms. London: Continuum.

MacArthur, C. A., Philippakos, Z. A., and Ianetta, M. (2015). Self-regulated strategy instruction in college developmental writing. Journal of Educational Psychology 107 (3), 855-867. https://doi.org/10.1037/edu0000011

Manchón, R. M., Roca de Larios, J., and Murphy, L. (2007). A review of writing strategies: Focus on conceptualizations and impact of first language. In A. D. Cohen and E. Macaro (Eds), Language Learner Strategies: 30 Years of Research and Practice, 229-250. Oxford: Oxford University Press.

O'Malley, J. M. and Chamot, A. U. (1990). Learning Strategies in Second Language Acquisition. Cambridge: Cambridge University Press. https://doi.org/10.1017/CBO9781139524490

Odlin, T. (1989). Language Transfer: Cross-Linguistic Influence in Language Learning. Cambridge: Cambridge University Press. https://doi.org/10.1017/CBO9781139524537

OFSTED. (2012). Moving English Forward: Action to Raise Standards in English. London. Retrieved from https://www.gov.uk/government/uploads/system/uploads/attachment_data/ file/181204/110118.pdf

OFSTED. (2013). Improving Standards in Literacy: A Shared Responsibility. London. Retrieved from www.ofsted.gov.uk/resources/120363

Oxford, R. (2011). Teaching and Researching Language Learning Strategies. Harlow: Pearson Education.

Oxford, R. (2017). Teaching and Researching Language Learning Strategies: SelfRegulation in Context. New York: Routledge.

Perkins, D. N. and Salomon, G. (1988). Teaching for transfer. Educational Leadership, 46 (1), 22-32.

Pomphrey, C. (2000). Language transfer and the Modern Foreign Languages curriculum. In Issues in Modern Foreign Languages Teaching, 269-282. London: RoutledgeFalmer.

Pomphrey, C. and Burley, S. (2009). Teacher language awareness education and pedagogy: A new discursive space. Language Awareness 18 (3-4), 422-433. https://doi.org/10.1080/09658410903197314

Pomphrey, C. and Moger, R. (1999). Cross-subject dialogue about language: Attitudes and perceptions of PGCE students of English and Modern Languages. Language Awareness 8 (3-4), 223-236. https://doi.org/10.1080/09658419908667131 
Prior, P. (2006). A sociocultural theory of writing. In C. A. MacArthur, S. Graham, and J. Fitzgerald (Eds), Handbook of Writing Research, 54-66. London: The Guilford Press.

Raimes, A. (1987). Language proficiency, writing ability, and composing strategies: A study of ESL college student writers. Language Learning 37 (3), 439-468. https://doi.org/10.1111/j.1467-1770.1987.tb00579.x

Rubin, J., Chamot, A. U., Harris, V., and Anderson, N. J. (2007). Intervening in the use of strategies. In A. D. Cohen and E. Macaro (Eds), Language Learner Strategies: 30 Years of Research and Practice, 141-160. Oxford: Oxford University Press.

Sasaki, M. (2000). Toward an empirical model of EFL writing processes: An exploratory study. Journal of Second Language Writing 9 (3), 259-291. https://doi.org/10.1016/S1060-3743(00)00028-X

Sasaki, M. (2002). Building an empirically-based model of EFL learners' writing processes. In S. Ransdell and M.-L. Barbier (Eds), New Directions for Research in L2 Writing, 49-80. Dordrecht: Kluwer Academic Publishers.

https://doi.org/10.1007/978-94-010-0363-6_3

Schunk, D. H. and Swartz, C. W. (1993). Goals and progress feedback: Effects on self-efficacy and writing achievement. Contemporary Educational Psychology 18, 337-354. https://doi.org/10.1006/ceps.1993.1024

Sengupta, S. (2000). An investigation into the effects of revision strategy instruction on L2 secondary school learners. System 28 (1), 97-113. https://doi.org/10.1016/S0346-251X(99)00063-9

Sharwood Smith, M. and Kellerman, E. (1986). Crosslinguistic influence in second language acquisition: An introduction. In E. Kellerman and M. Sharwood Smith (Eds), Crosslinguistic Influence in Second Language Acquisition, 1-9. Oxford: Pergamon Press.

Tinsley, T. and Board, K. (2017). Language Trends 2016/17: Language Teaching in Primary and Secondary Schools in England. London. Retrieved from https:// www.britishcouncil.org/sites/default/files/language_trends_survey_2017_0.pdf

Vygotsky, L. (1962). Thought and Language. Cambridge MA: MIT Press. https://doi.org/10.1037/11193-000

Yang, N.-D. (1999). The relationship between EFL learners' beliefs and learning strategy use. System 27 (4), 515-535. https://doi.org/10.1016/S0346-251X(99)00048-2

Zamel, V. (1983). The composing processes of advanced ESL students: Six case studies. Teachers of English to Speakers of Other Languages, Inc. (TESOL) 17 (2), 165-187. https://doi.org/10.2307/3586647 